\title{
Children as decision-makers in health care - An integrative review
}

\author{
Marjo Virkki ${ }^{* 1}$, Tarja Heino Tolonen ${ }^{1,2}$, Tapio Koskimaa ${ }^{3}$, Eija Paavilainen ${ }^{2,4}$ \\ ${ }^{1}$ The children's and women's division, Tampere University Hospital, Finland \\ ${ }^{2}$ School of Health Sciences, University of Tampere, Finland \\ ${ }^{3}$ Imaging Centre, Finland \\ ${ }^{4}$ Etelä-Pohjanmaa Hospital District, Finland
}

Received: September 1, 2014

Accepted: November 5, $2014 \quad$ Online Published: November 19, 2014

DOI: $10.5430 /$ cns.v3n1p47

URL: http://dx.doi.org/10.5430/cns.v3n1p47

\begin{abstract}
The aim of this integrative review is to describe a child's participation in the decision-making process related to treatment. The goal is to increase knowledge of the ways that healthcare professionals can use to support a child's decision-making ability. The data were gathered from the Medline and Cinahl databases and the data consisted of 23 articles which were published in scientific journals during 2002-2013. The articles were analyzed with an inductive content analysis. The results of the review show that a child's knowledge skills, wishes and values were often not taken into account and their participation was limited. Children were taken into account to varying degrees, depending on the time available and the individual healthcare professional. The personnel often made the treatment decisions on behalf of the families. This was greatly influenced by the attitudes of the personnel and parents and the ability of the healthcare personnel to work with child patients. The professional language used in discussions was shown to be an obstacle to flexible cooperation.
\end{abstract}

Key Words: Child, Minors, Decision-making, Participation, Healthcare personnel, Review

\section{Introduction}

In the United Nations (UN) Convention on the Rights of the Child (1989), it is stated that officials should take children into account in all actions and decisions concerning them and they should evaluate the effects of the decisions on the child. The child must always come first and the child's opinion must be heard. The child has the right to participate in decision-making concerning himself or herself based on their age and level of development. ${ }^{[1]}$ In Finland, as well as elsewhere in Europe, the rights of children are monitored by an ombudsman for children. The ombudsman acts based on the UN Convention on the Rights of the Child. ${ }^{[2,3]}$
In the Constitution of Finland (1999), children's basic rights include equal treatment, which also includes the right to have an influence on matters concerning them, based on their level of development. ${ }^{[4]}$ According to the law pertaining to a patient's position and rights (1992), the child's opinion must be asked when it is possible based on his or her age and level of development. When a child is able to decide about actions related to their treatment, the treatment decisions must be made together with them. The law mentions that information on a child's health and treatment cannot be given to their legal guardian if it is the child's own wish. ${ }^{[5]}$

In the ethics for the healthcare of children, it is stressed that a child should be asked for their consent when they have the

*Correspondence: Marjo Virkki; Email: marjo.virkki@pshp.fi; Address: The children's and women’s division, Tampere University Hospital, PL2000, 33521 Tampere, Finland. 
capability for it. The healthcare worker has the responsibility to inform the child about coming treatments and make the treatment experiences as positive as possible. The aim is to ask for the child's consent for the coming procedure. Healthcare workers must support the child in making decisions related to treatment. At the same time, healthcare workers must make sure that the child does not have to make decisions that surpass their understanding. ${ }^{[1,6,7]}$

The participation of a child in their treatment is diverse. The child's point of view, wishes and will are taken into account to varying degrees. Some of the healthcare workers who participated in the study thought that the child's view cannot always be taken into account, and some said that the child's view will be taken into account whenever it is possible from the point of view of their own work. ${ }^{[8]}$

Children are an important customer group in healthcare services but little research on children's healthcare experiences. The research is mainly focused on the parents' point of view. The problem in research on children is determining the methodological starting point, as there is a lack of suitable measurements. Research on children also faces the ethical challenge of children's ability to give consent. Views that state that a child cannot understand or describe their own experiences and their world due to their immaturity may decrease the amount of research focusing on children. ${ }^{[9]}$

In healthcare decision-making, the companionship and discussion between the patient and the professional is emphasized. The patient's opinion and viewpoints are taken into account in treatment and in decision-making. Explicit interaction and cooperation ensure that the decision-making is open and negotiable for the patient. ${ }^{[10]}$

Views on children's participation in decision-making vary greatly. In the protectionist point of view, parents should hinder and protect children from making bad decisions. Children are unqualified to make decisions especially related to treatment. Because of this, adults should defend and guard children. The liberalist view trusts in a child's right to self-determination and ability to make independent decisions. According to this viewpoint, children are a minority without citizenship rights. Especially in health care, a child's ability to discuss their own treatments and procedures is not appreciated. In the pragmatist view, the child's own opinion is respected and they are protected from questionable decisions. This view constitutes a synthesis of protectionist and liberalist approaches, trying to maintain a balance between a child's rights to self-determination and the parents' responsibilities. ${ }^{[11,12]}$

The patient's participation can be described as a continuum. It includes the different models of participation and decision-making and the levels of patient participation. In informed decision-making, experts give the patient sufficient information so that they can make decisions related to their treatment themselves. The patient makes the fi- nal decision himself/herself. In shared decision-making, the professional discusses the different treatment options together with the patient so that the decision-making is based on a shared understanding. In shared decision-making, the decision-making regarding treatment options is divided between the expert and the patient. The expert, "professionalas-agent", has influence when he or she has the technical expertise, and the child has the right to take part in the decision-making. According to paternalism, the expert knows what the best option for the patient is and information is shared to a limited extent with the patient. The patient's low authority means that the patient will not participate in decision-making and he or she will not be informed about procedures and treatment. In this case, the patient cannot give informed consent for coming treatments. ${ }^{[13]}$

\section{Aim}

The aim of this integrative review is to describe a child's participation in the decision-making process related to treatment. The goal is to increase knowledge of the ways that healthcare professionals can use to support a child's decision-making ability.

The literature review looks for answers to the following questions:

(1) How is a child taken into account in decision-making related to treatment?

(2) How can healthcare personnel support a child's participation and decision-making related to treatment?

\section{Methods}

The integrative review is used to collect and analyze existing research on the topic and to increase critical and systematic knowledge by using the above stated research questions in the analysis. The quality of the data was evaluated and the results were synthesized retrospectively as comprehensively as possible. ${ }^{[14-16]}$

The results from the international research articles and literature reviews selected for analysis in this study were analyzed with an inductive content analysis according to the research questions. Content analysis is a method that is based on the systematic and objective analysis of documents. ${ }^{[17,18]}$

\subsection{Data collection}

When defining the search terms, the MeSH (Medical Subject Heading) subject terminology was used, as well as reference books and articles from the subject area. The searches were complemented with natural language searches, and some searches were conducted with the help of an informaticist. ${ }^{[15]}$ 
Table 1: Inclusion and exclusion criteria for the data

\begin{tabular}{|c|c|}
\hline Inclusion criteria & Exclusion criteria \\
\hline $\begin{array}{l}\text { Child, young person or minor } \\
\text { in this study refers to a person } \\
\text { under } 18 \text { years old according } \\
\text { to the UN Convention on the } \\
\text { Rights of the Child }\end{array}$ & $\begin{array}{l}\text { Studies related to the mental } \\
\text { health, drug abuse, physical } \\
\text { abuse, terminal care and organ } \\
\text { donation of children and } \\
\text { young people }\end{array}$ \\
\hline $\begin{array}{l}\text { Scientific articles on the } \\
\text { decision-making of children } \\
\text { and minors related to } \\
\text { treatment }\end{array}$ & $\begin{array}{l}\text { Studies related solely to the } \\
\text { decision-making of legal } \\
\text { guardians, parents or } \\
\text { healthcare personnel }\end{array}$ \\
\hline \multicolumn{2}{|l|}{ Studies and systematic } \\
\hline \multicolumn{2}{|l|}{$\begin{array}{l}\text { Year of publication } 2000- \\
\text { today }\end{array}$} \\
\hline Article in English & \\
\hline
\end{tabular}

Search terms:

- Decision making and patient participation, consent

- Limit: yr = "2000-2013" and "preschool child (2 to 5 years)" or "child (6 to 12 years)" or "adolescent (13 to 18 years)"

Databases relevant to nursing science were the primary sources in the literature search. The inclusion and exclusion criteria for the data are presented in Table 1. Based on the searches, the Medline and Cinahl databases emerged as the best sources of articles when trying to answer the research questions (see Figure 1).

\subsection{Description of the data and quality evaluation}

Altogether 23 complete texts were included in the final analysis which answered the research questions and fulfilled the inclusion criteria. The choice of data was also influenced by availability. ${ }^{[14,19]}$ The articles were published during 20022013. The articles were written in North America $(n=11)$, Great Britain $(n=5)$, Sweden $(n=4)$, Israel $(n=1)$ and Ireland $(n=2)$.

The methodological approach in the articles selected for the review was qualitative in 14 cases, quantitative in four cases, and five articles were reviews. Based on the selection criteria and research questions, each study or review discussed the participation and decision-making of children or young persons in the context of healthcare. The articles often discussed the viewpoints of parents and healthcare personnel as well. In two studies, the decision-making and participation of families was focused on monitoring events during a doctor's appointment.

The quality of the data was evaluated according to the Grade (Grading quality of Evidence) classification. ${ }^{[20]}$ According to this classification, the grading quality of the 14 qualitative studies is D. Three quantitative studies were evaluated to have a grading quality of B, as in these studies the decisionmaking process had been developed with a new model based on the results. One quantitative study was evaluated to have a grading quality of $\mathrm{C}$. Two of the reviews were classified into the $\mathrm{B}$ class, one into the $\mathrm{C}$ class and two into the $\mathrm{D}$ class. Both of the reviews classified into the $\mathrm{B}$ class were strongly based on empirical research.

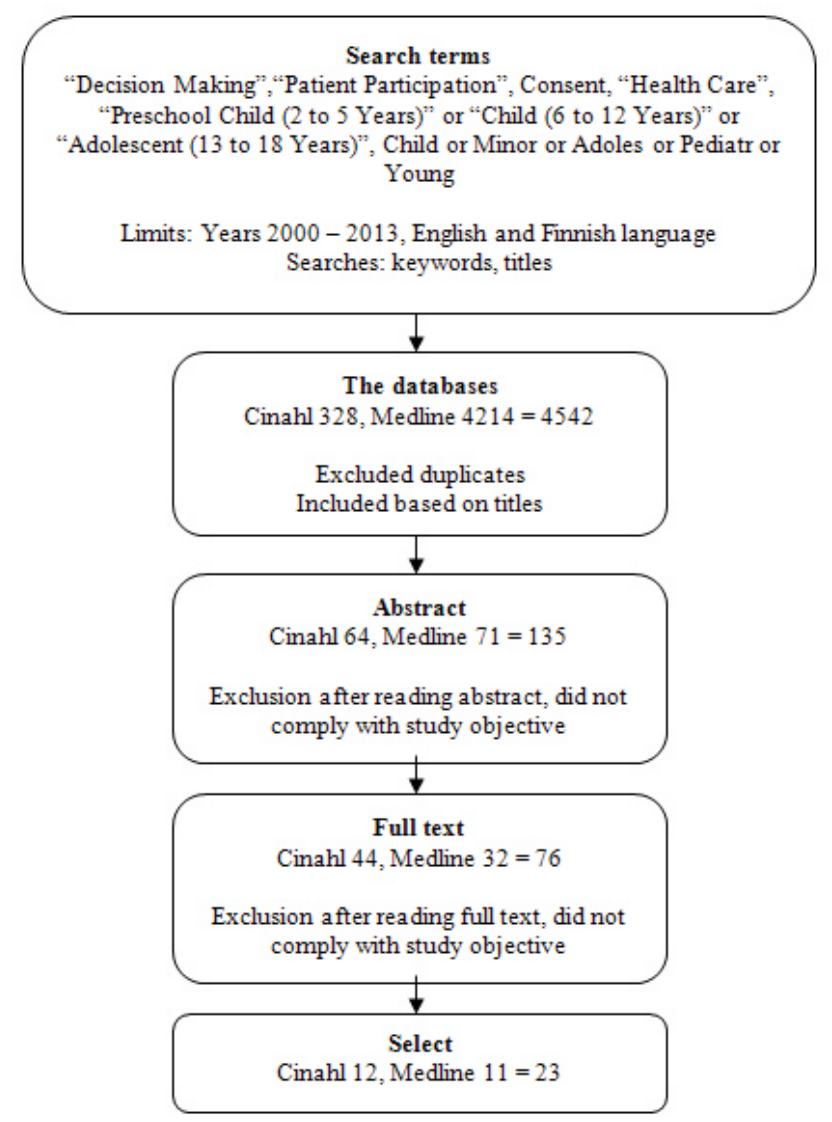

Figure 1: The literature search

Having a grading quality of $\mathrm{C}$ or $\mathrm{D}$ does not mean that a study or review is bad or that the results cannot be trusted. ${ }^{[20]}$ In nursing science, studies often focus on sensitive issues, which are better analyzed qualitatively than quantitatively. The research and understanding of nursing phenomena requires people's personal descriptions of experiences. ${ }^{[18]}$

The quality evaluation also included the impact factor (IF) of the publication and the citation index of the author. ${ }^{[21]}$ The IF values in 2012 varied between 0-5.391 and IF values within five years varied between 0-5.850. The citation values of the authors varied between $0-39$. The IF values for four articles are missing and their citation indexes varied between 2-14. The articles were included in the data because they described the phenomenon similarly to the other studies and reviews. 


\subsection{Data analysis}

The analysis of the research data was started by reading the articles carefully and getting familiarized with them. The essential results of the studies were written down in a table. The close reading was followed by an inductive content analysis. The analysis was guided by the research ques- tions, and simplified expressions were formed from the data. These expressions were compared with each other. Based on the comparison, subcategories were formed where similar expressions were combined into their own categories. Through this grouping, the categories were named (see Table 2). ${ }^{[17,18]}$

Table 2: Subcategories and categories

\begin{tabular}{lll}
\hline Subcategories & Categories \\
\hline Obstacles to participation and possibilities to have an influence & A child in the decision-making related to treatment \\
Limitations related to age criteria and level of development & \\
Weaknesses in communication & & $\begin{array}{l}\text { The readiness of the personnel to support the } \\
\text { Taking the child into account in decision-making and participation }\end{array}$ \\
The communicative skills of the healthcare personnel & \\
Ability to listen to a child & & \\
Obstacles to children's participation in health decision- making & & \\
\hline
\end{tabular}

\section{Results}

\subsection{A child in the decision-making related to treat- ment}

According to the umbrella categories, the results were focused on obstacles to participation and influence, age criteria and limitations related to level of development, as well as deficiencies in communication. The data also included descriptions of situations when the decision-making and participation took the child into account.

Obstacles to participation and possibilities to have an influence. The research results show that a child's knowledge capabilities, wishes and values are often not taken into account and their participation is prevented. ${ }^{[22-30]}$ Healthcare professionals make the decisions on behalf of the children and often on behalf of parents as well. ${ }^{[24,25,27,31]}$ The reasons behind this were the attitudes of the personnel and the parents ${ }^{[26,32,33]}$ and the desire to protect the child. ${ }^{[22,33]}$ The inexperience of the personnel in handling pediatric patients also has an effect on how actively the families participated in the decision-making. ${ }^{[24,34,35]}$

The healthcare personnel could not always find the time to ask about the child's view ${ }^{[23]}$ and the decision had to be made as quickly as possible. ${ }^{[25,27]}$ Sometimes there was no information available that would be targeted to children ${ }^{[23]}$ or the information was only targeted to the parents. ${ }^{[28]}$ The results of Runeson's (2007) study show that parents assume that a child has received the necessary information on the treatments. This assumption was shown to be erroneous based on the children's responses. ${ }^{[28]}$

Limitations related to age criteria and level of development. In the analysis of the child's position, the identifi- cation of cognitive skills and the child's age were emphasized. ${ }^{[23,27,34-37]}$ In Coyne's study, the communication of healthcare professionals was suggested to be more about identifying the knowledge skills of a child than their capability to understand the coming treatment events. ${ }^{[24]}$ Nurses valued the opinion of a child, but the child's capabilities and age limited the discussion. Some of the nurses wanted to get the parents' permission first before asking about the child's opinion. ${ }^{[1]}$ The participation of the child was influenced by reading skills and reading comprehension as well as legislation. ${ }^{[33]}$

Weaknesses in communication. The professional language used in discussions decreased the participation of children and parents and their willingness to make decisions. ${ }^{[24,35,38]}$ The children and parents felt that the healthcare personnel gave information in an unclear manner, so that they were not able to properly consider all the possible risks related to treatments. Existing guidelines regarding the sharing of information were complied with to varying degrees. ${ }^{[39]}$ Excessive information can also be an obstacle to participating in a clinical study for teenagers and young adults. ${ }^{[38]}$

Taking the child into account in decision-making and participation. Making a decision together or discussing their decision with parents was significant for children's self-esteem and their adherence to treatment. ${ }^{[31,40-42]}$ The positive attitude of parents and healthcare personnel had an effect on the child's participation. ${ }^{[31,42]}$ The decisionmaking related to treatment did not have a big importance for the children when their physical condition was bad or their treatment was just beginning. In such cases, the need for the support of others in decision-making was emphasized. $^{[29,43]}$ 
Decision-making and participation were tested in a study by Hankins et al. The patients and parents received written material, met a nurse, made a choice and then discussed the final decision with the doctor. The results showed that this method increased the patients' and parents' adherence to treatment. The children were also able to better express their opinion and even disagree with their parents. After the study ended, the method was kept in use at the hospital. ${ }^{[40]}$

\subsection{The readiness of the personnel to support the decision-making of a child}

Descriptions were chosen from the data which answered the research question of how the healthcare personnel can support a child's participation and decision-making related to treatment. The results emphasized the communicative skills of the personnel, their ability to listen to a child and their attitudes.

The communicative skills of the healthcare personnel. Suitable information reduces a child's fear and misunderstandings. ${ }^{[11,24,33]}$ Information is suitable when a child has a clear view of the nature and purpose of the treatment procedures and the effect of the treatment on his or her condition. ${ }^{[22,29,33]}$ Children who had received a lot of information and a possibility to participate in discussions regarding their treatment adhered to their treatment the best. ${ }^{[22,24]}$ Adherence to treatment was connected to the amount and quality of information. ${ }^{[27,28]}$ The children also expect to be informed on as many different issues as possible. ${ }^{[1,29]}$

Participation in treatment and decision-making cannot be tied to a certain age because cognitive development and willingness vary greatly among children. ${ }^{[11,26,34]}$ Giving information to children and young people is challenging because the amount of information should not be too small or too much. ${ }^{[43]}$ The information related to the illness, risks and the child's real understanding should be realistic. ${ }^{[34]}$ The behavior and communication skills of the healthcare personnel are key factors in the participation and decisionmaking of children in their treatment. ${ }^{[23,29,42]}$

Children are more calm and prepared for their treatment when they receive information and are consulted regarding their illness. ${ }^{[24,27]}$ The information is given according to the child's wishes and needs, and they are asked what they think about the planned treatment. The child needs time to think and to ask questions. ${ }^{[27]}$ Children and young people are given a chance to participate, and it should be a carefully considered process. ${ }^{[35]}$ According to studies, these considerations improve the child's ability to understand what their illness means.

Ability to listen to a child. The child should have the right to express their opinion ${ }^{[23,33,35]}$ and they should be given the possibility to make their own decisions. ${ }^{[22,33]}$ Listening to children is important and they should also be trusted. ${ }^{[11,22,23,26,35]}$ Children are able to provide a very dif-

Published by Sciedu Press ferent point of view to the planning of treatment. ${ }^{[11]}$

Children and minors should be given a chance to share the decision-making with their parents or healthcare personnel ${ }^{[22,34,40]}$ or they should be provided an opportunity to have someone else make decisions for them. ${ }^{[22,26,34,41]}$ The decision-making process depends on how the family in general makes decisions between them. ${ }^{[1,42]}$ Adherence to treatment and trust in the personnel increase when the child is given a chance to participate in the decisionmaking. ${ }^{[11,22,25]}$

Obstacles to children's participation in health decisionmaking. The primary obstacles to children's participation were the attitudes of the healthcare personnel and lack of time. The views and values of children and young people must be trusted. ${ }^{[23,34]}$ The nurses should encourage children to be active in decision-making, and it is also part of the ethical responsibilities of nurses. ${ }^{[11,38]}$ Healthcare personnel should test their own skills and give information and support their patients to participate in the decision-making related to their treatment. ${ }^{[34]}$

Nurses specializing in the treatment of children are in an important position regarding this issue. They can promote children's rights and participation in decision-making. ${ }^{[31]}$ When teamwork between children, parents and healthcare personnel is combined with research information, the decision-making process of children and minors can be developed. ${ }^{[33,38]}$

\section{Discussion}

\subsection{Discussion of results}

Based on the results, in some cases the healthcare personnel focused too much on identifying the cognitive skills of the child when examining the child's position, and the information and issues related to the actual treatment received less attention. Based on the results, the participation of a child cannot be tied to a certain age because cognitive development and willingness to participate vary greatly among children.

The results showed that the positive attitude of the personnel and parents and the possibility to make decisions enhance the child's self-esteem. Participation and discussing the decision were important for the child's adherence to treatment. A child or a minor has to be given a chance to let someone else make the decision on their behalf if they do not want to or have the strength to participate in the discussions.

Based on the results, the communicative skills and support of the personnel were significant. Adherence to treatment was connected to suitable information and the negotiating skills of the personnel. Clear and comprehensive information reduced the child's fear and misunderstandings. Giving information to children is challenging because the infor- 
mation should be given according to the child's wishes and needs.

The ability to listen to a child and the attitudes of the healthcare personnel emerged as significant issues in the data. Listening to a child and appreciating his or her opinions increased trust in the personnel and improved adherence to treatment. A child has the right to participate in their treatment and make decisions related to it. A child is a reliable source of information who can give a new point of view into the planning of treatment.

The attitudes of healthcare personnel emerged as a significant obstacle to a child's participation. The attitudes of the healthcare personnel were related to the lack of time and inexperience in treating children. The results did not show whether the uncertainty of the personnel in treating children and lack of time were related to each other.

The conflict that emerged in the study was related to the behavior of pediatric nurses. The need for nurses specializing in pediatrics was pointed out in the observation study by Hällström and Elander. According to them, pediatric nurses have experience of encouraging children to participate in decision-making and ensuring that the child's rights are taken into account. ${ }^{[31]}$ In Coyne's study, however, the biggest finding was that pediatric nurses made the decisions without hearing the opinions of children. ${ }^{[24]}$

In Runeson's study, parents assumed that their child had received enough information on the coming procedures. The results showed, however, that the children had not received enough information. ${ }^{[28]}$ According to the dissertation of Salmela, children cannot always express their fears related to hospitals because they want to protect their parents. Children do not want to add to their parents' worries by expressing their own. ${ }^{[4]}$

\subsection{Reliability of the review and ethical viewpoints}

The data was systematically gathered from databases that are relevant to nursing science by using the MeSH subject terminology, reference books and natural language searches. The search process was made as systematic as possible by conducting some searches with an informaticist. The informaticist assisted in specifying the search terms. The choice of search terms depended on the research questions defined in the research plan. The searches were limited to years 2000-2013 in order to find currently relevant research results. The instructions for conducting the study and the inclusion and exclusion criteria also affected the amount of articles chosen. The searches showed that research on the subject is scarce. For this reason, it was possible to read the majority of the abstracts and complete texts. ${ }^{[45]}$

The reliability was enhanced by carefully classifying the data in a table. The table helped to form a comprehensive view of the data and it helped in processing the data. Sev- eral findings from the data were gathered into the umbrella categories, so that the analysis became more repeatable and answers were found to the research questions. The limitations in the study were the small sample sizes, as is common in qualitative research, and the small amount of data in general. ${ }^{[17,46]}$

The quality of the articles selected for the study turned out to be quite diverse based on the evaluation criteria. Even though the grading quality of the evidence of the majority of the articles was evaluated as $\mathrm{D}$, the impact factor values and/or numbers of citation indexes supported the choice of the articles included in the study. ${ }^{[20,21]}$

The research articles and literature reviews chosen for the study were mainly in English and electronically available. This can cause language or publication bias, and there is the possibility that significant studies have been left outside of the searches. In this study, based on the coherent results, the language and publication bias are unlikely to be present. As a research method, an integrative review has limitations which are acknowledged in this study. Research on children is scarce due to methodological challenges and prejudices, which causes limitations for the selection of studies and the analysis of results. ${ }^{[14-16]}$ Research studies focusing on different age groups were not analyzed separately in this study, even though the research group acknowledges that the cognitive, social and emotional skills and knowledge of 2-18 years old children vary greatly between different age groups. $^{[47]}$

The study was conducted according to the rules of good scientific practice. The collection and analysis of data was as precise and responsible as possible. The study was based on a research plan. The criteria in the research plan were followed according to the phases presented earlier in this study. The quality evaluation of the research articles and reviews was conducted taking into account ethical viewpoints. The different stages of the study have been described as specifically as possible so that the reader can evaluate the author's choices. $^{[17,18,48]}$

\section{Conclusions and topics for further re- search}

This study supports the view that the participation of children in the decision-making in healthcare is irregular. The study results can be utilized in practice for developing treatment discussions with children and minors. The training of healthcare personnel should emphasize the identification and understanding of the cognitive skills, wishes and values of children.

The positive attitude of the staff and parents, the possibility to participate in discussions as an equal, and the opportunity to participate in decision-making were factors that increased the child's self-esteem and adherence to treatment. 
The child must also be given a chance to refuse to take part in the decision-making or negotiation related to treatment. To achieve this, the staff should have good communication skills, the ability to listen to the child and experience of treating pediatric patients.

The need to further develop and study the decision-making process emerged as a topic for further research that can help in increasing the participation of children in the context of healthcare. The results from the intervention study by Hankins et al that focused on decision-making and participation are worth testing. In this model, the patients and parents received written material, met a nurse, made the choice and then discussed the final decision with the doctor. The results of the study and its effects were significant for both the patients and parents. ${ }^{[40]}$

In the study by Hankins, et al., the patients and parents were given written material. ${ }^{[40]}$ In the follow-up studies, it should be determined first what kind of written material exists for child patients and their parents. It should be studied how the instructions could be developed and standardized so that a child can understand the material. Writing such material is demanding because different age groups should have different material available that takes into account their age and level of comprehension.

In the future, more research is needed on how nursing personnel take children into account in treatment decisionmaking. For instance, by using an observation study, it is possible to target the possible weaknesses related to the discussions from the children's and their parents' points of view. This kind of approach would also give information on the training needs of the healthcare personnel.

\section{Conflicts of Interest Disclosure}

The authors declare that they have no competing interest.

\section{References}

[1] Convention on the Rights of the Child [Internet]. Adopted and opened for signature, ratification and accession by General Assembly resolution 44/25 of 20 November 1989 [cited 2010 Nov 27]. Available from: www2.ohchr.org/english/law/crc.htm

[2] The Law on the Ombudsman for Children [Internet]. 21.12.2004/1221 [cited 2010 Nov 27]. Available from: htpp://www.finlex.fi

[3] European Network of Ombudspersons for Children (ENOC) [Internet]. Established in 1997 [cited 2012 Mar 29]. Available from: http://www.crin.org/enoc

[4] The Constitution of Finland [Internet]. 11 June 1999/731 [cited 2010 Nov 27]. Available from: htpp://www.finlex.fi

[5] Act on the Status and Rights of Patients [Internet]. 17.8.1992/785 [cited 2010 Nov 27]. Available from: htpp://www.finlex.fi

[6] Leino-Kilpi H, Välimäki M. Ethics in Nursing. 5th rev. ed. Porvoo: WSOY; 2009.

[7] Parekh SA. Child consent and the law: an insight and discussion into the law relating to consent and competence. Child: Care, Health \& Development. 2006; 33(1): 78-82. http://dx.doi .org/10.1111 $/ j .1365-2214.2006 .00641 . x$

[8] Pekki A, Tamminen T. The Conditions of the Child. Vammala; Kunnallisalan kehittämissäätiön tutkimusjulkaisut, nro 33; 2002.

[9] Pelander T, Nuuttila L-M, Salanterä S, et al. Child as Information Source: the Survey of the Dissertations of the Nursing Science that have been done in Finland. Hoitotiede. 2006; 18(4): 160-171.

[10] Lindfors P. The Patient's part to the Decision-Making with the General Practitioner's and the Homoeopath's Reception. Sosiaalilääketieteellinen aikakauslehti. 2004; 41: 185-198.

[11] Baston J. Healthcare decisions: a review of children's involvement. Paediatric Nursing. 2008; 20(3): 24-6. http://dx.doi.org/10. 7748/paed2008.04.20.3.24.c6517

[12] Lowden J. Children's rights: a decade of dispute. Journal of Advanced Nursing. 2002; 37(1): 100-7. http://dx. doi .org/10.10 $46 / j \cdot 1365-2648.2002 .02049 \cdot x$

[13] Thompson AGH. The Meaning of patient involvement and participation in health care consultations: A taxonomy. Social Science \& Medicine. 2007; 64: 1297-1310. http://dx.doi.org/10.1016 /j.socscimed.2006.11.002

Published by Sciedu Press
[14] Rew L. The systematic review of literature: synthesizing evidence for practice. Journal for Specialists in Pediatric Nursing. 2011; 16(1): 64-9. http://dx.doi.org/10.1111/j.1744-6155.20 $10.00270 . \mathrm{x}$

[15] Holopainen A, Hakulinen-Viitanen T, Tossavainen K. Systematic review - a method for nursing research. Nurse Researcher. 2008; 16(1): 72-83. http://dx.doi.org/10.7748/nr2008.10.16. 1.72.c6754

[16] Pudas-Tähkä S-M, Axelin A. Delimitation of the Subject of the Systematic Literature Review, Search Terms and Evaluation of the Abstract. Turun yliopisto: Hoitotieteen laitoksen julkaisuja A: 51; 2007.

[17] Jones ML. Application of systematic review methods to qualitative research: practical issues. Journal of Advanced Nursing. 2004; 48(3): 271-8. http://dx.doi.org/10.1111/j.1365-2648.20 $04.03196 . x$

[18] Elo S, Kyngäs H. The qualitative content analysis process. Journal of Advanced Nursing. 2008; 62(1): 107-115. http://dx. doi .org /10.1111/j.1365-2648.2007.04569.x

[19] Duffy ME. Systematic Reviews: Their Role and Contribution to Evidence-based Practice. Clinical Nurse Specialist. 2005; 19(1): 15-7. http://dx.doi .org/10.1097/00002800-200501000-0 0005

[20] Higgins JPT, Green S (editors). Cochrane Handbook for Systematic Reviews of Interventions Version 5.1.0. The Cochrane Collaboration[Internet]. 2011 Mar [cited 2012 Mar 29]. Available from: http://handbook. cochrane.org

[21] Griffiths P, Norman I. What is a nursing research journal? International Journal of Nursing Studies. 2011; 48(11): 1311-4. http: //dx.doi.org/10.1016/j.ijnurstu.2011.09.006

[22] Alderson P, Sutcliffe K, Curtis K. Children's Competence to Consent to medical Treatment. Hastings Center Report. 2006; 36(6): 25-34. http://dx.doi.org/10.1353/hcr.2006.0000

[23] Coyne I. Children's participation in consultations and decisionmaking at health service level: A review of the literature. International Journal of Nursing Studies. 2008; 45: 1682-9. http: //dx.doi.org/10.1016/j.ijnurstu.2008.05.002

[24] Coyne I. Consultation with children in hospital: children, parents' and nurses' perspectives. Journal of Clinical Nursing. 2006; 15: 6171. http://dx.doi.org/10.1111/j.1365-2702.2005.01247 . $\mathrm{x}$ 
[25] Karnieli-Miller O, Eisikovits Z. Physician as partner or salesman? Shared decision-making in real-time encounters. Social Science \& Medicine. 2009; 69: 1-8. http://dx.doi.org/10.1016/j.soc scimed.2009.04.030

[26] Knopf JM, Hornung RW, Slap GB, et al. Views of treatment decision making from adolescents with chronic illnesses and their parents: a pilot study. Health Expectations. 2008; 11: 343-54. http://dx.doi.org/10.1111/j.1369-7625.2008.00508.x

[27] Runeson I, Hallström I, Elander G, et al. Children's Participation in the Decision-Making Process During Hospitalization: an observational study. Nursing Ethics. 2002; 9(6): 583-98. http://dx.doi .org/10.1191/0969733002ne553oa

[28] Runeson I, Måsterson E, Enskär K. Children's Knowledge and Degree of Participation in Decision Making When Undergoing a Clinical Diagnostic Procedure. Pediatric Nursing. 2007; 33(6): 505-11. PMid:18196714.

[29] Stegenga K, Ward-Smith P. The Adolescent Perspective on Participation in Treatment Decision Making: A Pilot Study. Journal of Pediatric Oncology Nursing. 2008; 25(2): 112-7. http://dx.doi .org/10.1177/1043454208314515

[30] Miller VA, Baker JN, Leek AC, et al. Adolescent perspectives on phase I cancer research. Pediatric Blood \& Cancer. 2013; 60(5): 873-8. http://dx.doi.org/10.1002/pbc. 24326

[31] Hällström I, Elander G. Decision-making during hospitalization: parents' and children's involvement. Journal of Clinical Nursing. 2004; 13: 367-75. http://dx.doi.org/10.1046/j.1365-270 2.2003.00877.x

[32] Coyne I, Harder M. Children's participation in decision-making: Balancing protection with shared decision-making using a situational perspective. Journal of Child Health Care. 2011; 15(4): 312-9. http://dx . doi .org/10.1177/1367493511406570

[33] Mårtenson EK, Fägerskiöld AM. A review of children's decisionmaking competence in health care. Journal of Clinical Nursing. 2007; 17: 3131-41. http://dx.doi.org/10.1111/j.1365-270 2.2006.01920.x

[34] Alderson P. Competent children? Minor consent to health care treatment and research. Social Science \& Medicine. 2007; 65: 2272-83. http://dx.doi.org/10.1016/j.socscimed.2007.08.005

[35] Cox ED, Smith MA, Brown RL. Evaluating Deliberation in Pediatric Primary Care. Pediatrics. 2007; 120: 68-77. http://dx.doi .org/10.1542/peds. 2006-2602

[36] Geller G, Tambor ES, Bernhardt BA, et al. Informed Consent for Enrolling Minors in Genetic Susceptibility Research: A Qualitative Study of At-risk Children's and Parents' Views About Chil- dren's Role in Decision-making. Journal of Adolescent Health. 2003; 32: 260-71. http://dx.doi.org/10.1016/S1054-139 $\mathrm{X}(02)$ 00459-7

[37] Miller VA, Harris D. Measuring children's decision-making involvement regarding chronic illness management. Journal of Pediatric Psychology. 2012; 37(3): 292-306. http://dx.doi.org/10.10 93/jpepsy/jsr097

[38] Read K, Fernandez CV, Gao J, et al. Decision-Making by Adolescents and Parents of Children With Cancer Regarding Health Research Participation. Pediatrics. 2009; 124(3): 959-65. http: //dx.doi.org/10.1542/peds. 2008-2878

[39] Reynolds WW, Nelson RM. Risk perception and decision processes underlying informed consent to research participation. Social Science \& Medicine. 2007; 65: 2105-15. http://dx.doi.org/10. 1016/j.socscimed. 2007.06 .021

[40] Hankins J, Hinds P, Day S, et al. Therapy Preference and DecisionMaking Patients With Severe Sickle Cell Anemia and Their Families. Pediatric Blood and Cancer. 2007; 48(7): 705-10. http: //dx.doi.org/10.1002/pbc. 20903

[41] Miller VA, Reynolds WW, Nelson RM. Parent-Child Roles in Decision Making About Medical Research. Ethics \& Behavior. 2008; 18(2-3): 161-81. http://dx.doi.org/10.1080/10508420802 063947

[42] Snethen JA, Broome ME, Knafl K, et al. Family Patterns of Decision-Making in Pediatric Clinical Trials. Research In Nursing \& Health. 2006; 29: 223-32. http://dx.doi.org/10.1002/nur 20130

[43] Kelsey J, Abelson-Mitchell N, Skirton H. Perceptions of young people about decision making in the acute healthcare environment. Pediatric Nursing. 2007; 19(6): 14-8.

[44] Salmela M. Hospital-related fears and coping strategies in 4-6years-old children. Helsinki; Helsingin yliopisto, lääketieteellinen tiedekunta, kliininen laitos; 2010.

[45] Malmivaara A. Systemised Literature Review - Tool for the Catching of the Study Display. Duodecim. 2002; 118: 877-979. PMID: 12238165 .

[46] Woods L, Priest H, Roberts P. An overview of three different approaches to the interpretation of qualitative data. Part 2: practical illustrations. Nurse Researcher. 2002; 10(1): 43-51. http://dx.d oi.org/10.7748/nr2002.10.10.1.43.c5878

[47] Nurmi JE, Ahonen T, Lyytinen H, et al. The Human Development and Psychology. Helsinki: WSOY; 2006.

[48] Tutkimuseettinen neuvottelukunta. Good Scientific Practice and Dealing of its Offence With. Helsinki: Edita Prima Oy; 2002. 